Al Maal : Journal of Islamic Economics and Banking

http://jurnal.umt.ac.id/index.php/jieb

E-ISSN : $2580-3816$

Vol : 2 No. 1 Bulan Januari Tahun 2021

Hlm : $193-211$

DOI $\quad$ : 10.31000/almaal.v1i2.3754

\title{
Analisis Pengambilan Keputusan Pembelian Kosmetik Berlabel Halal MUI pada Generasi Millenial
}

\author{
Badriyyatus Sholikhah ${ }^{1}$, Resfa Fitri ${ }^{2 *}$, Yekti Mahanani ${ }^{3}$ \\ ${ }^{1,2,3}$ Departemen Ilmu Ekonomi Syariah, IPB University, Indonesia \\ *resfa_fitri@apps.ipb.ac.id
}

\begin{abstract}
Millennial generation is consumption oriented generation. They are smart, trendsetter, and brand conscious. One of the products which is consumed by millennial generation is cosmetic products. Consumption of global halal cosmetics had a significant increased by 4.9 percent in 2018 or reached USD 64 billion where Indonesia is the second country as a global halal cosmetics consumer with a total expenditure of USD 4 billion. This study aims to analyze the factors influencing millennial generation in their decision to purchase halal MUI certified cosmetics. This research conducted in East Jakarta, Indonesia with 100 respondents. The method used in this research is logistic regression analysis. The result shows that halal knowledge, halal awareness, and brand image had a significant positive influence on the decision to purchase cosmetics labeled Halal MUI by the millennial generation of East Jakarta. It is expected that domestic cosmetic manufacturers will immediately certify and labeling halal MUI as a form of consumer protection. This is also important in increasing domestic cosmetic production, and to make Indonesia becomes manufacturer of halal cosmetic products.
\end{abstract}

Keywords: Millennial Generation; Cosmetics; Halal Label; Logistic Regression Analysis.

\section{ABSTRAK}

Generasi milenial adalah generasi yang berorientasi pada konsumsi, cerdas, trendsetter, dan sadar akan merek. Salah satu produk yang dikonsumsi oleh generasi milenial adalah kosmetik. Konsumsi kosmetik halal global mengalami peningkatan yang signifikan yaitu naik sebesar 4.9 persen di tahun 2018 atau mencapai USD 64 miliar dimana Indonesia merupakan negara kedua terbesar sebagai konsumen kosmetik halal global dengan total belanja USD 4 miliar. Penelitian ini bertujuan untuk menganalisis faktor-faktor yang memengaruhi generasi milenial dalam pengambilan keputusan pembelian kosmetik berlabel halal MUI. Penelitian dilakukan di Jakarta Timur dengan mengambil sampel sebanyak 100 responden. Metode yang digunakan dalam penelitian ini adalah analisis regresi logistik. Hasil penelitian menunjukkan bahwa pengetahuan halal, halal awareness, dan citra merek berpengaruh signifikan positif terhadap pengambilan keputusan pembelian kosmetik berlabel halal MUI yang dilakukan oleh generasi milenial Kota Jakarta Timur. Diharapkan agar para produsen kosmetik dalam negeri segera melakukan sertifikasi dan labelisasi halal MUI sebagai bentuk perlindungan konsumen. Hal ini penting dalam rangka pengembangan produksi kosmetik dalam negeri, dan menjadikan Indonesia sebagai produsen produk kosmetik halal.

Kata kunci : Generasi milenial, Kosmetik; Label halal; Analisis regresi logistic. 


\section{Pendahuluan}

Industri kosmetik merupakan salah satu sektor industri halal yang saat ini sedang diprioritaskan pemerintah. Hal tersebut dibuktikan dengan ditempatkannya industri kosmetik sebagai sektor andalan oleh Kementerian Perindustrian Republik Indonesia yang tertuang dalam Rencana Induk Pembangunan Industri Nasional (RIPIN) tahun 2015-2035. Menurut Kementerian Perindustrian Republik Indonesia (2018), pertumbuhan industri kosmetik dalam negeri disebabkan karena adanya permintaan besar dari pasar domestik dan ekspor seiring tren masyarakat yang mulai memperhatikan produk perawatan tubuh sebagai kebutuhan utama. Saat ini, produk kosmetik sudah menjadi kebutuhan primer, terutama bagi kaum wanita yang merupakan target utama dari industri kosmetik.

Meskipun terdapat pertumbuhan pada industri kosmetik dalam negeri, Indonesia belum termasuk ke dalam 10 besar negara produsen yang fokus pada perkembangan kosmetik dan farmasi halal. Namun, di sisi lain terdapat peningkatan yang signifikan pada konsumsi kosmetik halal global, yaitu naik sebesar 4.9 persen di tahun 2018. Indonesia merupakan negara dengan jumlah penduduk muslim terbesar di dunia dan menempati posisi kedua sebagai konsumen kosmetik halal global (State of The Global Islamic Economy Report 2019/2020).

Jumlah penduduk yang cukup besar merupakan salah satu potensi dan keuntungan bagi Indonesia. Kementerian Pemberdayaan Perempuan dan Perlindungan Anak (KP3A,2018) menjelaskan bahwa peningkatan jumlah penduduk produktif yang signifikan merupakan fenomena bonus demografi. Pada era ini, mayoritas penduduk produktif adalah generasi $\mathrm{Y}$ atau biasa disebut dengan generasi milenial. Menurut Susenas (2017), generasi Y atau generasi milenial jumlahnya sebesar 33.75 persen dari total penduduk Indonesia atau mencapai sekitar 88 juta jiwa. Jumlah tersebut lebih dominan dibandingkan generasi lainnya yaitu generasi pasca milenial yang biasa disebut dengan generasi $\mathrm{Z}$ jumlahnya baru mencapai 29.23 persen, kemudian generasi $\mathrm{X}$ yang jumlahnya mencapai 25.74 persen juga generasi baby boom + veteran (tua) yang jumlahnya mencapai 11.27 persen. Gambar 1 di bawah ini merupakan komposisi penduduk menurut generasi.

Gambar 1 Komposisi penduduk menurut generasi (persen)

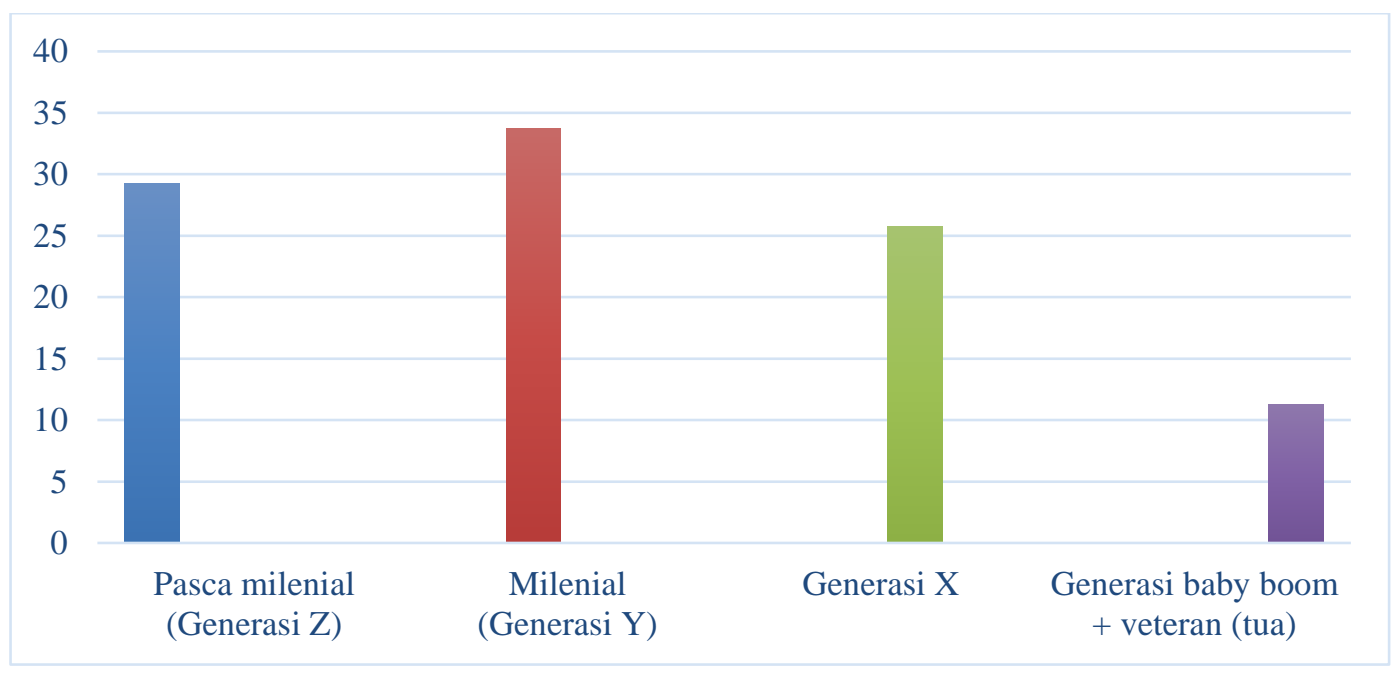

Sumber: Survei Sosial Ekonomi Nasional (Susenas), BPS 2017 
Berdasarkan data dari KP3A (2018) generasi milenial yang tinggal di daerah perkotaan memiliki persentase lebih tinggi yaitu sekitar 55 persen dibandingkan dengan generasi milenial yang tinggal di daerah perdesaan. Jumlahnya mengikuti pola penduduk Indonesia yang umumnya sudah mulai berpindah dari masyarakat perdesaan menjadi masyarakat perkotaan. Masyarakat perdesaan yang berpindah menjadi masyarakat perkotaan mengakibatkan nilai-nilai tradisional menjadi semakin terpinggirkan oleh budaya urban. Masyarakat perdesaan yang dulunya sederhana kini menjadi masyarakat yang konsumtif, khususnya masyarakat generasi milenial yang consumption oriented dan sadar akan merek (Khalek dan Ismail 2015).

Jumlah generasi milenial di Indonesia menyebar secara merata di seluruh provinsi yaitu antara 31 persen di Provinsi Jawa Tengah sampai dengan 38.10 persen di Papua Barat. DKI Jakarta memiliki persentase generasi milenial terbesar kedua setelah Papua Barat yaitu 37.30 persen (Survei Sosial Ekonomi Nasional (Susenas), BPS 2017)

Menurut Badan Pusat Statistik (2018), kota yang memiliki jumlah penduduk terbesar di Indonesia adalah Kota Administrasi Jakarta Timur. Jumlah penduduk yang besar tersebut menunjukkan pangsa pasar yang luas karena permintaan terhadap produk akan meningkat serta akan mendorong pertumbuhan ekonomi (Jannah 2018). Tabel 1 dibawah ini merupakan urutan kota dan kota administrasi menurut jumlah penduduk.

Tabel 1 Kota dan kota administrasi menurut jumlah penduduk tahun 2016

\begin{tabular}{lll}
\hline \multicolumn{1}{c}{ Kota } & \multicolumn{1}{c}{ Provinsi } & \multicolumn{1}{c}{ Jumlah Penduduk } \\
\hline Kota Administrasi Jakarta Timur & DKI Jakarta & 2868910 \\
Kota Surabaya & Jawa Timur & 2862406 \\
Kota Bekasi & Jawa Barat & 2803283 \\
Kota Administrasi Jakarta Barat & DKI Jakarta & 2496002 \\
Kota Bandung & Jawa Barat & 2490662 \\
\hline
\end{tabular}

Sumber: BPS 2018 (diolah)

Generasi milenial adalah generasi yang consumption oriented, generasi cerdas, trendsetter, dan sadar akan merek (Khalek dan Ismail 2015). Generasi milenial memiliki jumlah yang dominan dibandingkan dengan generasi lainnya dan berada pada rentang usia 20 hingga 40 tahun yang merupakan usia produktif. Presentase generasi milenial terbesar kedua berada pada wilayah DKI Jakarta, dimana Kota Jakarta Timur merupakan kota administrasi yang memiliki jumlah penduduk terbanyak di Indonesia.

Indonesia merupakan salah satu pasar kosmetik yang cukup besar yaitu berada pada posisi kedua sebagai konsumen kosmetik halal global sehingga bisnis ini akan prospektif bagi produsen yang ingin mengembangkannya di dalam negeri. Namun, saat ini Indonesia belum fokus terhadap perkembangan kosmetik halal dalam negeri. Padahal kosmetik halal merupakan industri yang menjanjikan terlebih gaya hidup halal sedang menjadi tren di berbagai belahan dunia. Melihat potensi yang besar ini, Indonesia diharapkan tidak hanya menjadi konsumen kosmetik halal global tetapi juga produsen kosmetik halal dalam skala global.

Dalam rangka mendorong perkembangan industri kosmetik halal, produsen perlu mengetahui apa saja faktor-faktor yang memengaruhi pengambilan keputusan pembelian kosmetik berlabel halal seorang konsumen khususnya konsumen generasi milenial Kota Jakarta Timur agar seorang produsen dapat menyusun strategi pemasarannya dengan lebih baik. 


\section{KAJIAN LITERATUR}

\section{Generasi Millenial dan Konsumsi Produk Halal}

Istilah milenial pertama kali dicetuskan oleh William Strauss dan Neil dalam bukunya yang berjudul Millennials Rising: The Next Great Generation (2000). Jika didasarkan pada Generation Theory yang dicetuskan oleh Karl Mannheim pada tahun 1923, generasi milenial adalah generasi yang lahir pada rasio tahun 1980 sampai dengan 2000. Generasi milenial juga disebut sebagai generasi Y (Kementerian Pemberdayaan Perempuan dan Perlindungan Anak 2018). Pendapat ini mirip dengan pendapat Stafford dan Griffis (2008) yang menyatakan bahwa generasi milenial adalah populasi yang lahir antara tahun 1980 sampai dengan 2000.

Salah satu ciri dari generasi milenial adalah penggunaan yang meningkat serta keakraban dengan media, komunikasi serta teknologi digital. Keakraban pada kemajuan teknologi mengakibatkan generasi milenial bersifat informatif, kreatif, memiliki passion serta produktif. Komunikasi yang terbuka, pengguna media sosial yang fanatik, kehidupan yang sangat dipengaruhi oleh kemajuan teknologi juga lebih terbuka pada pandangan ekonomi serta politik merupakan karakteristik dari generasi milenial. Oleh karena itu, generasi ini sangat reaktif dengan adanya perubahan lingkungan di sekitarnya (Subandowo, 2017).

Berdasarkan penelitian Khalek dan Hayati (2015), faktor-faktor yang mempengaruhi generasi millenial (Y) dalam mengkonsumsi produk halal adalah sikap positif tentang halal, lingkungan sosial seperti keluarga dan teman, serta sikap kehatihatian dalam penerimaan produk halal. Dijelaskan bahwa sikap positif terhadap produk halal merupakan hal yang paling penting dalam berperilaku dalam mengkonsumsi produk halal.

Sikap konsumen generasi muda dalam memilih produk halal selama ini belum banyak dibahas dan diteliti. Sikap positif generasi muda terhadap produk halal bisa dipengaruhi oleh agama/kepercayaan, mass media dan lingkungan sekitar (Khalek, 2014).

Studi dan literatur sebelumnya menginformasikan bahwa norma-norma subjective, perilaku penerimaan produk halal, serta religiusitas berpengaruh terhadap konsumsi produk halal (Elseidi, 2018). Sikap kaum muslim terhadap produk halal ini kemungkinan berhubungan dengan aturan tentang halal dalam Islam, serta keuntungan apabila mengkonsumsi produk halal dan dan kerugian apabila mengkonsumsi produk tidak halal.

Dalam hal keputusan pembelian produk halal, Elseidi (2018) menjelaskan bahwa fakor kesehatan sangat dominan. Oleh sebab itu dalam hal ini produsen produk halal harus secara transparan menjelaskan proses pembuatan produk, sehingga konsumen merasa yakin dengan kehalalan produk tersebut.

\section{Kosmetik halal}

Berdasarkan Keputusan Kepala Badan Pengawas Obat dan Makanan (BPOM) RI Nomor HK.00.05.4.1745 Tentang Kosmetik, kosmetik merupakan bahan yang digunakan pada tubuh manusia di bagian luar seperti epidermis, bibir, kuku, rambut juga organ genital di bagian luar atau mukosa mulut dan gigi terutama untuk mewangikan, membersihkan, memperbaiki bau badan, memelihara atau melindungi tubuh pada kondisi baik, dan mengubah penampilan. 
Berdasarkan Surat Keputusan Lembaga Pengkajian Pangan Obat-Obatan dan Kosmetika Majelis Ulama Indonesia (LPPOM MUI) tentang Revisi Ketentuan Kelompok Produk Bersertifikat Halal MUI Berdasarkan SK15/Dir/LPPOM MUI/V/11 Nomor: SK67/Dir/LPPOM MUI/XII/11, kosmetik dikelompokkan menjadi: 1) Perawatan Tubuh (sabun, lotion, obat kumur, pasta gigi, dll), 2) Perawatan Rambut (sampo, kondisioner, dll), 3) Dekoratif (maskara, blush on, lipstick, eye shadow, dll), dan 4) Parfum.

Menurut Undang-Undang Republik Indonesia Nomor 33 Tahun 2014 Tentang Jaminan Produk Halal, produk yang sudah dinyatakan halal sesuai dengan syariat atau ajaran Islam adalah produk halal. LPPOM MUI (2017) menjelaskan bahwa kepastian status kehalalan perlu diberikan agar dapat menenteramkan batin seorang konsumen ketika mengonsumsi produk. Status kehalalan pada produk kosmetika, obat-obatan, pangan serta produk lainnya diperoleh dengan melakukan sertifikasi halal MUI.

Sertifikat Halal MUI merupakan fatwa tertulis dari Majelis Ulama Indonesia (MUI) yang menyatakan kehalalan suatu produk sesuai dengan ajaran dan syariat Islam. Sertifikat ini adalah syarat agar sebuah kemasan produk mendapatkan izin untuk mencantumkan label halal dari instansi pemerintah yang berwenang. Menurut Astogini et al. (2011), labelisasi halal adalah label yang menginformasikan kepada pengguna bahwa sebuah produk benar-benar halal. Selain itu, UU RI Nomor 33 tahun 2014 mendefinisikan bahwa label halal merupakan tanda halalnya suatu produk.

Menurut Sugiarto et al. (2000), permintaan adalah jumlah barang yang diminta oleh pasar. Hal tersebut diasumsikan karena setiap manusia pasti memiliki kebutuhan. Dalam memenuhi kebutuhan tersebut maka muncul permintaan akan barang atau jasa sebagai alat untuk memenuhi kebutuhan. Kebutuhan seorang konsumen dapat mendorong untuk melakukan pembelian.

Kotler dan Keller (2009) menjelaskan bahwa terdapat lima tahap pada proses keputusan pembelian yaitu pengenalan masalah, pencarian informasi, evaluasi alternatif, keputusan pembelian, dan perilaku pascapembelian. Proses tersebut telah dimulai sebelum tindakan pembelian sebenarnya. Selanjutnya, dalam waktu yang lama dapat berlanjut setelah pembelian. Pemasar tidak hanya memusatkan perhatian pada keputusan pembelian, namun harus pada keseluruhan proses pembelian. Berikut ini merupakan model lima tahap proses pembelian konsumen.

Gambar 2 Model lima tahap proses pembelian konsumen

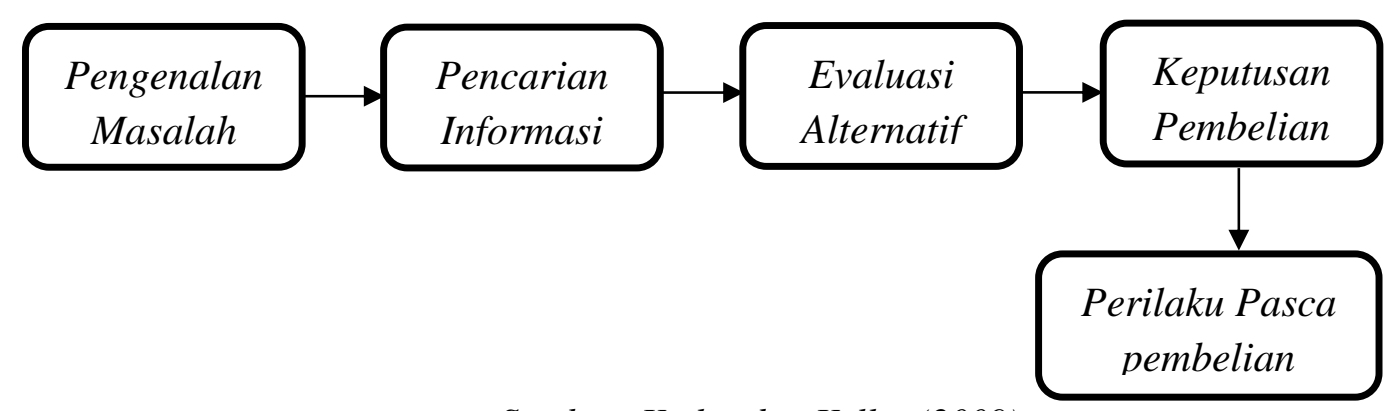

Sumber: Kotler dan Keller (2009) 
Gambar 3 menunjukkan bahwa saat melakukan pembelian, seorang konsumen akan melewati seluruh lima tahap, namun konsumen sering membalik urutan beberapa tahap atau bahkan menghilangkan dalam pembelian yang lebih rutin. Berikut ini akan dijelaskan tahapan keputusan pembelian konsumen:

1) Pengenalan Masalah

Proses pembelian diawali ketika seorang konsumen sadar akan adanya kebutuhan atau masalah yang disebabkan oleh rangsangan eksternal maupun internal. Rangsangan eksternal mengakibatkan terdapat pemikiran mengenai kemungkinan dalam melakukan pembelian seperti diskusi dengan seorang teman atau adanya suatu iklan. Selanjutnya, pada rangsangan internal, seorang konsumen memiliki kebutuhan normal yang dapat mendorong untuk melakukan pembelian seperti haus dan lapar yang naik menuju tingkat maksimum.

\section{2) Pencarian Informasi}

Konsumen yang memiliki ketertarikan terhadap suatu produk dapat memperoleh informasi dari beberapa sumber, yaitu sumber pribadi (tetangga, teman, keluarga), sumber komersial (wiraniaga, website, iklan), sumber publik (pencarian internet, media sosial, media massa) serta sumber pengalaman (penggunaan produk).

\section{3) Evaluasi Alternatif}

Dalam membantu memahami proses evaluasi, terdapat konsep dasar, yakni seorang konsumen akan berusaha untuk memuaskan kebutuhannya. Kemudian konsumen akan mencari suatu manfaat dari solusi produk. Selain itu, konsumen akan melihat setiap produk sebagai sekelompok atribut yang mampu memberikan suatu manfaat, dimana manfaat tersebut diperlukan seorang konsumen dalam memuaskan kebutuhan.

4) Keputusan pembelian

Seorang konsumen biasanya akan membeli suatu merek yang paling mereka sukai. Namun, terdapat dua faktor yang dapat menyebabkan seseorang akan bertindak untuk melakukan pembelian atau hanya sekedar niat pembelian. Faktor tersebut adalah faktor situasional yang tidak konsumen harapkan dan sikap orang lain. Faktor-faktor seperti manfaat produk yang konsumen harapkan, harga, dan pendapatan dapat menimbulkan niat pembelian seorang konsumen. Namun, sebuah kejadian yang tidak dapat diduga dapat membuat niat pembelian tersebut berubah. Niat pembelian tidak selalu menimbulkan pilihan pembelian yang aktual.

\section{5) Perilaku Pascapembelian}

Perilaku pascapembelian adalah tahap dimana dua kemungkinan dapat dialami oleh seorang konsumen, yaitu ketidakpuasan dan kepuasan terhadap suatu pilihan yang telah ditentukannya. Dekatnya kemampuan suatu produk dengan harapan seorang konsumen tentang produk tersebut akan menghasilkan kepuasan pada konsumen. Tingkah laku konsumen berikutnya dapat dipengaruhi oleh ketidakpuasan dan kepuasan seorang konsumen terhadap sebuah produk. 


\section{Metode Penelitian}

Penelitian ini menggunakan data primer dan sekunder. Data primer diperoleh dengan cara menyebar kuesioner kepada responden yang berdomisili di Kota Jakarta Timur dengan mempertimbangkan Jakarta Timur sebagai kota administrasi dengan jumlah penduduk terbesar di Indonesia. Hal tersebut mengindikasikan bahwa terdapat pangsa pasar yang cukup besar di Kota Jakarta Timur. Sedangkan data sekunder didapatkan dari buku, jurnal, skripsi, internet, dan studi literatur untuk melengkapi data primer. Penelitian ini dilaksanakan selama bulan Januari hingga Maret 2020.

Metode penarikan sampel dalam penelitian ini adalah metode non probability sampling, dimana setiap unsur dalam populasi tidak memiliki peluang atau kesempatan yang sama untuk dijadikan sebagai sampel. Teknik non probability sampling yang digunakan adalah purposive sampling atau sampel tertentu yang telah sesuai dan memenuhi segala persyaratan yang dibutuhkan. Penentuan sampel dilakukan dengan pertimbangan tertentu, yakni dengan kriteria responden merupakan penduduk generasi milenial yang berdomisili di Kota Jakarta Timur, berjenis kelamin perempuan dan sudah pernah membeli dan menggunakan produk kosmetik dengan jenis kosmetik berupa perawatan wajah/ make up/ dekoratif. Penentuan jumlah sampel dari populasi menggunakan metode Slovin. Rumus Slovin adalah sebagai berikut:

$$
\mathrm{n}=\frac{N}{1+N \cdot e^{2}}
$$

Keterangan:

n : Jumlah sampel

$\mathrm{N} \quad$ : Jumlah populasi

e : Nilai kritis yang digunakan (10\%)

Jumlah populasi penduduk Kota Jakarta Timur yang berjenis kelamin perempuan dan termasuk kelompok generasi milenial. Tabel 2 dibawah ini menunjukkan jumlah penduduk perempuan milenial Kota Jakarta Timur.

Tabel 2 Penduduk perempuan milenial Kota Jakarta Timur

\begin{tabular}{lll}
\hline & Kelompok Umur & Jumlah \\
\hline $20-24$ & 115355 & \\
$25-29$ & 139217 & \\
$30-34$ & 140966 & \\
$35-39$ & 129718 \\
\hline
\end{tabular}

Sumber: BPS 2018 (diolah)

Berdasarkan data BPS pada Tabel 2, penduduk perempuan milenial di Kota Jakarta Timur adalah sebanyak 525256 jiwa. Sehingga jumlah sampel adalah:

$$
\mathrm{n}=\frac{525256}{\left(1+525256\left(0,1^{2}\right)\right)}=99.98 \approx 100
$$

\section{Analisis Deskriptif}

Riduwan dan Sunarto (2011) menjelaskan bahwa analisis deskriptif digunakan untuk menjelaskan atau menggambarkan identitas umum dan karakteristik responden. Dalam penelitian ini, analisis deskriptif digunakan untuk data kualitatif yang diperoleh melalui pengisian kuesioner oleh responden. Analisis deskriptif yang digunakan adalah modus. Santoso (2003) menjelaskan bahwa modus pada prinsipnya adalah menghitung 
jumlah data yang paling sering muncul. Analisis deskriptif mengidentifikasi karakteristik konsumen yang disajikan dalam bentuk tabulasi. Data dikelompokkan berdasarkan jawaban yang sama dalam suatu tabel, kemudian dipersentasekan berdasarkan jumlah responden. Faktor dominan dari masing-masing peubah yang diteliti dapat dilihat pada persentase terbesar.

\section{Analisis Regresi Logistik}

Hosmer dan Lemeshow (2000) mendefinisikan bahwa regresi logistik merupakan sebuah pendekatan untuk membuat model prediksi seperti halnya Ordinary Least Squares (OLS) regression atau regresi linear. Perbedaannya adalah pada regresi logistik, peneliti memprediksi variabel terikat yang berskala dikotomi. Skala dikotomi merupakan skala data nominal yang memiliki dua kategori, misal: Ya dan Tidak, Tinggi dan Rendah atau Baik dan Buruk. Selanjutnya, OLS memiliki asumsi atau mewajibkan syarat bahwa error varians (residual) harus terdistribusi normal. Sedangkan regresi logistik tidak membutuhkan asumsi tersebut karena regresi logistik sudah mengikuti distribusi logistik.

Menurut Firdaus et al. (2011), analisis regresi logistik bertujuan untuk menentukan peluang kejadian bahwa dari beberapa alternatif yang sudah tersedia, seorang individu yang mempunyai karakteristik tertentu akan memilih suatu pilihan. Salah satu ukuran asosiasi dan penduga parameter yang didapatkan dari analisis regresi logistik adalah dengan odds ratio. Odds merupakan peluang terjadinya suatu kejadian dibandingkan dengan peluang tidak terjadinya kejadian tersebut. Ratio mengidentifikasikan seberapa mungkin dalam kaitannya dengan nilai odds munculnya kejadian sukses pada suatu kelompok dibandingkan dengan kelompok lain.

Persamaan regresi logistik dibawah ini untuk mengetahui faktor-faktor yang memengaruhi generasi milenial Kota Jakarta Timur dalam pengambilan keputusan pembelian kosmetik berlabel halal MUI:

$Y_{i}=Y_{n}\left(\frac{P_{i}}{1-P_{i}}\right)=\beta_{0}+\beta_{1} P H_{i}+\beta_{2} H A_{i}+\beta_{3} C M_{i}+\beta_{4} M S_{i}+\beta_{5} K P_{i}+\beta_{6} H P_{i}+\varepsilon_{i}$

Keterangan:

$Y_{i} \quad:$ Keputusan pembelian responden terhadap produk kosmetik

$P_{i} \quad$ : Produk kosmetik berlabel halal MUI (nilai=1)

$1-P_{i} \quad$ : Produk kosmetik tidak berlabel halal MUI (nilai=0)

$\beta_{0} \quad$ : Intersep

$\beta_{i} \quad$ : Parameter peubah X

PH : Pengetahuan Halal (skala likert)

HA : Halal Awareness (skala likert)

CM : Citra Merek (skala likert)

MS : Media Sosial (skala likert)

KP : Kualitas Produk (skala likert)

HP : Harga Produk (skala likert)

$\varepsilon \quad:$ Galat atau error

i : Responden ke-i $(\mathrm{i}=1,2,3, . ., \mathrm{n})$ 


\section{HASIL DAN PEMBAHASAN}

\section{Karakteristik Generasi Milenial Kota Jakarta Timur}

Responden pada penelitian ini berjumlah 100 responden, dengan pembagian 50 responden generasi milenial menggunakan produk kosmetik berlabel halal MUI dan 50 responden generasi milenial menggunakan produk kosmetik tidak berlabel halal MUI. Karakteristik responden yang dibahas meliputi usia, agama, daerah domisili, pendidikan terakhir, pekerjaan, pemasukan per bulan, pengeluaran pembelian kosmetik per bulan, sumber informasi, dan merek produk kosmetik. Hal tersebut dapat dilihat pada Tabel 3.

Tabel 3. Karakteristik responden

\begin{tabular}{|c|c|c|}
\hline Karakteristik Responden & Klasifikasi & Persentase (\%) \\
\hline \multirow[t]{4}{*}{ Usia } & $20-24$ & 57 \\
\hline & $25-29$ & 22 \\
\hline & $30-34$ & 14 \\
\hline & $35-39$ & 7 \\
\hline \multirow[t]{6}{*}{ Agama } & Islam & 87 \\
\hline & Protestan & 8 \\
\hline & Katolik & 1 \\
\hline & Hindu & 1 \\
\hline & Buddha & 2 \\
\hline & Konghucu & 1 \\
\hline \multirow[t]{10}{*}{ Daerah domisili } & Cakung & 3 \\
\hline & Cipayung & 22 \\
\hline & Ciracas & 25 \\
\hline & Duren Sawit & 8 \\
\hline & Jatinegara & 4 \\
\hline & Kramat Jati & 12 \\
\hline & Makasar & 5 \\
\hline & Matraman & 4 \\
\hline & Pasar Rebo & 14 \\
\hline & Pulo Gadung & 3 \\
\hline \multirow[t]{4}{*}{ Pendidikan terakhir } & SMA/Sederajat & 39 \\
\hline & D3 & 22 \\
\hline & $S 1$ & 35 \\
\hline & $S 2$ & 4 \\
\hline \multirow[t]{5}{*}{ Pekerjaan } & Mahasiswa & 29 \\
\hline & Wirausaha & 11 \\
\hline & Pegawai Negeri & 7 \\
\hline & Pegawai Swasta & 45 \\
\hline & Ibu Rumah Tangga & 8 \\
\hline \multirow[t]{5}{*}{ Pemasukan per bulan } & $<2600000$ & 33 \\
\hline & $2600000-5200000$ & 53 \\
\hline & $5200001-7800000$ & 8 \\
\hline & $7800001-13000000$ & 5 \\
\hline & $>13000000$ & 1 \\
\hline Pengeluaran pembelian & $<100000$ & 8 \\
\hline \multirow[t]{4}{*}{ kosmetik per bulan } & $100000-250000$ & 56 \\
\hline & $250001-500000$ & 33 \\
\hline & $500001-1000000$ & 2 \\
\hline & $>1000000$ & 1 \\
\hline
\end{tabular}




\begin{tabular}{lll}
\hline Sumber informasi & Media sosial & 64 \\
& Teman/ Keluarga & 43 \\
& Televisi & 15 \\
& Lainnya & 1 \\
\hline
\end{tabular}

Sumber: Data Primer 2020, diolah

Berdasarkan usia, karakteristik responden pada penelitian ini berada pada rentang usia 20 hingga 39 tahun. Responden dengan jumlah terbanyak menggunakan kosmetik dengan presentase 57 persen berada pada rentang usia 20 hingga 24 tahun. Pada karakter berdasarkan agama, responden terbanyak pada penelitian ini merupakan pemeluk agama Islam dengan presentase 87 persen.

Karakteristik dengan daerah domisili dikategorikan berdasarkan kecamatan yang berada di Jakarta Timur. Mayoritas responden berdomisili di wilayah Ciracas sebanyak 25 orang atau setara 25 persen. Selanjutnya, terdapat karakteristik responden berdasarkan pendidikan terakhir yang dibagi menjadi empat kategori yaitu SMA/ Sederajat, D3, S1 dan S2. Jumlah responden terbanyak yaitu pada kategori SMA/ Sederajat sebesar 39 persen. Karakteristik responden berdasarkan pekerjaan dibagi menjadi lima kategori yaitu Mahasiswa Wirausaha, Pegawai Negeri, Pegawai Swasta, dan Ibu Rumah Tangga. Mayoritas responden yaitu sebesar 45 persen bekerja sebagai pegawai swasta. Selanjutnya, karakteristik responden berdasarkan pemasukan per bulan menunjukkan responden terbanyak mempunyai pemasukan antara Rp 2600 000-Rp 5200 000, yitu sebanyak 53\%. Sedangkan jumlah responden terbanyak mempunyai pengeluaran pembelian kosmetik per bulan adalah pada jumlah pengeluaran antara Rp 100 000- Rp 250 000. Karakteristik responden berdasarkan sumber informasi dibagi ke dalam empat kategori sumber informasi, yaitu media sosial, teman/ keluarga, televisi, dan lainnya. Mayoritas responden mendapatkan sumber informasi dari media sosial yaitu sebanyak 64 responden dari total 100 responden.

Pembagian pemasukan atau kelas pendapatan terdapat pada Tabel 4 yang mengacu pada data Badan Pendidikan dan Pelatihan Keuangan Kementerian Keuangan (BPPK Kemenkeu 2015).

Tabel 4. Kelas pendapatan

\begin{tabular}{ll}
\hline \multicolumn{1}{c}{ Kelas } & \multicolumn{1}{c}{ Rentang Pendapatan $(\boldsymbol{R p})$} \\
\hline Menengah ke bawah & $<2600000$ \\
Menengah pertama & $2600000-5200000$ \\
Menengah kedua & $5200001-7800000$ \\
Menengah ketiga & $7800001-13000000$ \\
Menengah ke atas & $>13000000$ \\
\hline
\end{tabular}

Sumber: BPPK Kemenkeu 2015

Karakteristik berdasarkan merek produk terdiri dari dua kategori, yaitu kategori produk kosmetik tidak berlabel halal MUI dan kategori produk kosmetik berlabel halal MUI. Kategori kosmetik tidak berlabel halal MUI sebesar 38 persen didominasi oleh responden dengan merek Maybelline dan kategori produk kosmetik berlabel halal MUI sebesar 58 persen didominasi oleh responden dengan merek Wardah. Data ini menunjukkan bahwa kosmetik berlabel halal MUI lebih diminati oleh generasi milenial yang menggunakan merek Wardah. Hal tersebut dapat dilihat pada Tabel 5. 
Tabel 5. Karakteristik responden berdasarkan merek produk kosmetik

\begin{tabular}{lllll}
\hline \multicolumn{1}{c}{ Kategori } & \multicolumn{2}{c}{$\begin{array}{c}\text { Kosmetik tidak berlabel } \\
\text { halal MUI (\%) }\end{array}$} & $\begin{array}{c}\text { Kosmetik berlabel } \\
\text { halal MUI (\%) }\end{array}$ \\
& & & \\
\hline $\begin{array}{l}\text { Berdasarkan merek } \\
\text { produk kosmetik }\end{array}$ & Merek & $\%$ & Merek & $\%$ \\
& & & & \\
& Maybelline & 38 & Wardah & 58 \\
& Loreal & 26 & Emina & 18 \\
& Nature Republic & 16 & Make Over & 10 \\
& Etude & 8 & Pixy & 4 \\
& Focallure & 4 & Safi & 4 \\
& The Body Shop & 4 & Ponds & 4 \\
& Innisfree & 4 & Sariayu & 2 \\
& Total & 100 & Total & 100 \\
& & & & \\
& &
\end{tabular}

Sumber: Data Primer 2020, diolah

\section{Distribusi Responden dalam Membeli Kosmetik}

Distribusi responden dalam membeli kosmetik berdasarkan, dibedakan atas: (a) berdasarkan karakteristik demografi; (b) berdasarkan karakteristik ekonomi; dan (c) berdasarkan pekerjaan.

\section{Karakteristik Demografi}

Berikut ini adalah distribusi responden dalam membeli kosmetik berdasarkan ka66rakteristik demografi (usia, agama, daerah domisili, dan pendidikan terakhir).

Tabel 6. Distribusi responden dalam membeli kosmetik berdasarkan karakteristik sosial

\begin{tabular}{cccc} 
Kategori & Keterangan & $\begin{array}{c}\text { Kosmetik tidak berlabel } \\
\text { halal MUI (\%) }\end{array}$ & $\begin{array}{c}\text { Kosmetik berlabel } \\
\text { halal MUI (\%) }\end{array}$ \\
& & & \\
\hline Usia & $20-24$ tahun & 54 & 60 \\
& $25-29$ tahun & 24 & 20 \\
$30-34$ tahun & 14 & 14 \\
$35-39$ tahun & 8 & 6 \\
Total & 100 & 100 \\
& & & 92 \\
Agama & Islam & 14 & 2 \\
& Protestan & 2 & 0 \\
& Katolik & 0 & 2 \\
& Hindu & 2 & 2 \\
& Buddha & 0 & 2 \\
& Konghucu & 100 & 100 \\
& Total & & 2 \\
& Cakung & 16 & 28 \\
& Cipayung & 28 & 22 \\
& Ciracas & 8 & 6 \\
& Duren Sawit & 4 & 4
\end{tabular}




$\begin{array}{cccc} & \text { Kramat Jati } & 12 & 12 \\ \text { Makasar } & 6 & 4 \\ \text { Matraman } & 4 & 4 \\ \text { Pasar Rebo } & 16 & 14 \\ & \text { Pulo Gadung } & 2 & 4 \\ & \text { Total } & 100 & 100 \\ \text { Pendidikan Terakhir } & \text { SMA/Sederajat } & 44 & 34 \\ & \text { D3 } & & 20 \\ & \text { S1 } & 24 & 44 \\ \text { S2 } & 26 & 2 \\ & \text { Total } & 6 & 100\end{array}$

\section{Sumber: Data Primer 2020, diolah}

Berdasarkan kategori Usia, responden yang menggunakan kosmetik tidak berlabel halal MUI sebesar 54 persen didominasi oleh responden pada rentang usia 20 hingga 24 tahun dan kategori responden yang menggunakan kosmetik berlabel halal MUI sebesar 60 persen juga didominasi oleh responden pada rentang usia 20 hingga 24 tahun. Data ini menunjukkan bahwa baik kosmetik berlabel halal MUI maupun kosmetik tidak berlabel halal MUI lebih diminati oleh generasi milenial pada rentang usia 20 hingga 24 tahun.

Selanjutnya, untuk kategori agama, Jumlah responden yang menggunakan kosmetik tidak berlabel halal MUI sebesar 82 persen didominasi oleh responden yang menganut agama Islam dan kategori responden yang menggunakan kosmetik berlabel halal MUI sebesar 92 persen juga didominasi oleh responden yang menganut agama Islam. Data ini menunjukkan bahwa baik kosmetik berlabel halal MUI maupun kosmetik tidak berlabel halal MUI lebih diminati oleh generasi milenial yang menganut agama Islam.

Untuk kategori daerah domisili, responden pada penelitian ini berdomisili di Kota Jakarta Timur. Kota Jakarta Timur terbagi menjadi 10 kecamatan yaitu Cakung, Cipayung, Ciracas, Duren Sawit, Jatinegara, Kramat Jati, Makasar, Matraman, Pasar Rebo dan Pulo Gadung. Berdasarkan daerah domisili, kategori responden yang menggunakan kosmetik tidak berlabel halal MUI sebesar 28 persen didominasi oleh responden yang berdomisili di Kecamatan Ciracas dan kategori responden yang menggunakan kosmetik berlabel halal MUI sebesar 28 persen didominasi oleh responden yang berdomisili di Kecamatan Cipayung. Data ini menunjukkan bahwa kosmetik berlabel halal MUI lebih diminati oleh generasi milenial yang berdomisili di Kecamatan Cipayung.

Untuk kategori pendidikan terakhir, menunjukkan bahwa responden yang menggunakan kosmetik tidak berlabel halal MUI sebesar 44 persen didominasi oleh responden yang memiliki pendidikan terakhir SMA/ Sederajat dan responden yang menggunakan kosmetik berlabel halal MUI sebesar 44 persen didominasi oleh responden yang memiliki pendidikan terakhir S1. Data ini menunjukkan bahwa kosmetik berlabel halal MUI lebih diminati oleh generasi milenial yang memiliki pendidikan terakhir S1. 


\section{Karakteristik Ekonomi}

Distribusi responden dalam membeli kosmetik berdasarkan karakteristik ekonomi (Pemasukan per bulan dan Pengeluaran pembelian kosmetik per bulan), terdapat pada Tabel 7.

Tabel 7. Distribusi responden dalam membeli kosmetik berdasarkan karakteristik ekonomi (Pemasukan per bulan dan Pengeluaran pembelian kosmetik per bulan)

\begin{tabular}{cccc}
\hline Kategori & Keterangan & $\begin{array}{c}\text { Kosmetik tidak berlabel } \\
\text { halal MUI (\%) }\end{array}$ & $\begin{array}{c}\text { Kosmetik berlabel } \\
\text { halal MUI (\%) }\end{array}$ \\
\hline Pemasukan/bulan & $<2,6$ & 38 & 28 \\
(Rp juta) & $2,6-5,2$ & 48 & 58 \\
& $5,2-7,8$ & 8 & 8 \\
& $7,8-13$ & 6 & 4 \\
& $>13$ & 0 & 2 \\
Total & 100 & 100 \\
pengeluaran & & & 4 \\
per bulan (Rp 000) & $100-250$ & 12 & 60 \\
& $250-500$ & 52 & 32 \\
& $500-1000$ & 2 & 2 \\
& $>1000$ & 0 & 2 \\
& Total & 100 & 100 \\
\hline
\end{tabular}

Sumber: Data Primer 2020, diolah

Tabel 7 menunjukkan bahwa kategori responden yang menggunakan kosmetik tidak berlabel halal MUI sebesar 48 persen didominasi oleh responden dengan pemasukan per bulan Rp 2600000 hingga Rp 5200000 dan kategori responden yang menggunakan kosmetik berlabel halal MUI sebesar 58 persen juga didominasi oleh responden dengan pemasukan per bulan Rp 2600000 hingga Rp 5200 000. Data ini menunjukkan bahwa baik kosmetik berlabel halal MUI maupun kosmetik tidak berlabel halal MUI lebih diminati oleh generasi milenial dengan pemasukan per bulan Rp 2600000 hingga Rp 5 200000.

Hasil penelitian ini juga menunjukkan bahwa kategori responden yang menggunakan kosmetik tidak berlabel halal MUI sebesar 52 persen didominasi oleh responden dengan pengeluaran pembelian kosmetik Rp 100000 hingga Rp 250000 per bulan dan kategori responden yang menggunakan kosmetik berlabel halal MUI sebesar 60 persen juga didominasi oleh responden dengan pengeluaran pembelian kosmetik Rp 100000 hingga Rp 250000 per bulan. Data ini menunjukkan bahwa baik kosmetik berlabel halal MUI maupun kosmetik tidak berlabel halal MUI lebih diminati oleh generasi milenial dengan pengeluaran pembelian kosmetik per bulan sebesar Rp 100000 hingga Rp 250000. 


\section{Karakteristik Pekerjaan}

Distribusi responden dalam membeli kosmetik berdasarkan karakteristik pekerjaan responden dapat dilihat pada Tabel 8.

Tabel 8. Distribusi responden dalam membeli kosmetik berdasarkan karakteristik pekerjaan

\begin{tabular}{llll}
\hline Kategori & Keterangan & $\begin{array}{l}\text { Kosmetik tidak berlabel } \\
\text { halal MUI }(\%)\end{array}$ & $\begin{array}{l}\text { Kosmetik berlabel } \\
\text { halal MUI }(\%)\end{array}$ \\
\hline Pekerjaan & Mahasiswa & 36 & 22 \\
& Wirausaha & 16 & 6 \\
& Pegawai Negeri & 6 & 8 \\
& Pegawai Swasta & 38 & 52 \\
& Ibu RmhTangga & 4 & 12 \\
& Total & 100 & 100
\end{tabular}

Sumber: Data Primer 2020, diolah

Tabel 8 menunjukkan karakteristik berdasarkan pekerjaan masing-masing responden. Data menunjukkan bahwa kategori responden yang menggunakan kosmetik tidak berlabel halal MUI sebesar 38 persen didominasi oleh responden yang bekerja sebagai pegawai swasta dan kategori responden yang menggunakan kosmetik berlabel halal MUI sebesar 52 persen juga didominasi oleh responden yang bekerja sebagai pegawai swasta. Data ini menunjukkan bahwa baik kosmetik berlabel halal MUI maupun kosmetik tidak berlabel halal MUI lebih diminati oleh generasi milenial yang bekerja sebagai pegawai swasta.

\section{Faktor-Faktor yang Memengaruhi}

Data penelitian diolah dengan analisis regresi logistik, dimana tidak ada asumsi sebelum dilakukan pengolahan data. Pengolahan data pada penelitian ini menggunakan SPSS 23 dengan menguji nilai Nagelkerke R Square dan Hosmer and Lemmeshow untuk mengetahui persentase ketepatan data yang dapat dijelaskan oleh model. Uji ketepatan prediksi model pada responden generasi milenial Kota Jakarta Timur yang membeli dan tidak membeli produk kosmetik berlabel halal MUI serta nilai signifikansi untuk mengetahui faktor-faktor yang memengaruhi keputusan pembelian generasi milenial Kota Jakarta Timur terhadap produk kosmetik berlabel halal MUI. Interpretasi hasil signifikansi menggunakan odds ratio.

Berikut adalah hasil analisis faktor-faktor yang memengaruhi keputusan pembelian generasi milenial Kota Jakarta Timur terhadap produk kosmetik berlabel halal MUI: 
Tabel 9. Faktor-faktor yang memengaruhi generasi milenial Kota Jakarta Timur dalam pengambilan keputusan pembelian kosmetik berlabel halal MUI

\begin{tabular}{cccc}
\hline Variabel & B (koef) & P-Value (Sig.) & Odds Ratio Exp (B) \\
\hline Pengetahuan Halal & .647 & $.001^{* * *}$ & 1.909 \\
Halal Awareness & .307 & $.064^{*}$ & 1.360 \\
Citra Merek & .622 & $.020^{* *}$ & 1.863 \\
Media Sosial & .081 & .507 & 1.084 \\
Kualitas Produk & .033 & .872 & 1.034 \\
Harga Produk &. .421 & .133 & .656 \\
\hline
\end{tabular}

Sumber : Data Primer 2020, diolah

$$
\begin{array}{r}
\text { Keterangan } \quad \text { : } \\
\quad \text { Signifikan pada taraf nyata } 10 \% \\
\\
* * * \text { Signifikan pada taraf nyata } 5 \% \\
\end{array}
$$

Berdasarkan Tabel 9, terdapat tiga variabel yang signifikan pada taraf nyata 10 persen, 5 persen dan 1 persen yaitu variabel halal awareness, citra merek, dan pengetahuan halal. Variabel halal awareness signifikan pada taraf nyata 0.064 , variabel citra merek signifikan pada taraf nyata 0.020 , dan variabel pengetahuan halal signifikan pada taraf nyata 0.001 .

Variabel pengetahuan halal berpengaruh positif dan signifikan pada taraf nyata 1 persen dengan nilai odds ratio 1.909 sehingga apabila tingkat pengetahuan halal generasi milenial Kota Jakarta Timur tentang produk kosmetik berlabel halal MUI lebih tinggi satu satuan, maka peluang generasi milenial Kota Jakarta Timur untuk membeli kosmetik berlabel halal MUI 1.909 kali lebih besar dari peluang tidak membeli kosmetik berlabel halal MUI. Hal ini relevan dengan penelitian yang dilakukan oleh Paramita (2016) yang menyatakan bahwa pengetahuan halal berpengaruh signifikan terhadap perilaku mengonsumsi produk kosmetik berlabel halal MUI.

Variabel halal awareness berpengaruh positif dan signifikan pada taraf nyata 10 persen dengan nilai odds ratio 1.360 sehingga dapat diinterpretasikan bahwa semakin tinggi tingkat kesadaran halal (halal awareness) generasi milenial Kota Jakarta Timur, maka peluang responden dalam membeli kosmetik berlabel halal MUI 1.360 kali lebih besar dibandingkan peluang tidak membeli kosmetik berlabel halal MUI. Hasil ini relevan dengan penelitian yang dilakukan oleh Khansa (2019) yang menyatakan bahwa halal awareness memiliki pengaruh signifikan terhadap keputusan pembelian kosmetik berlabel halal MUI.

Variabel citra merek berpengaruh positif dan signifikan pada taraf nyata 5 persen dengan nilai odds ratio 1.863 sehingga dapat diinterpretasikan bahwa setiap tingkat citra merek pada kosmetik berlabel halal MUI lebih tinggi satu satuan, maka peluang generasi milenial Kota Jakarta Timur untuk membeli kosmetik berlabel halal MUI 1.863 kali lebih besar dibanding peluang tidak membeli kosmetik berlabel halal MUI. Penelitian ini didukung oleh penelitian yang dilakukan oleh Alfian dan Marpaung (2017) yang menyatakan bahwa terdapat pengaruh yang signifikan antara citra merek dengan keputusan pembelian. 


\section{Implikasi Kebijakan}

Berdasarkan penelitian yang telah dilakukan, bahwa lebih mudah menemukan generasi milenial yang menggunakan produk kosmetik berlabel halal MUI dibandingkan dengan yang menggunakan produk kosmetik tidak berlabel halal MUI. Hal tersebut sesuai dengan kondisi Indonesia sebagai negara yang berpenduduk Muslim terbesar di dunia, yang mengutamakan produk berlabel halal MUI.

Pembelian produk kosmetik halal pada generasi milenial dalam penelitian ini dipengaruhi oleh pengetahuan generasi milenial akan halal atau tidaknya suatu produk, kesadaran generasi milenial akan pentingnya mengonsumsi produk kosmetik halal, dan citra dari merek produk kosmetik halal yang digunakan. Oleh karena itu, produsen kosmetik dalam negeri hendaknya segera melakukan sertifikasi dan labelisasi halal MUI sebagai bentuk perlindungan konsumen. Hal ini penting dalam rangka mendorong perkembangan industri kosmetik halal dalam negeri, sehingga produk kosmetik halal dalam negeri harus dapat bersaing di pasar domestik maupun internasional.

Pemerintah melalui PP RI No.31 Tahun 2019 Tentang Peraturan Pelaksanaan UU No.33 Tahun 2014 tentang Jaminan Produk Halal menyatakan bahwa produk yang masuk, beredar, dan diperdagangkan di wilayah Indonesia wajib bersertifikat halal dikecualikan bagi pelaku usaha yang memproduksi produk dari bahan yang diharamkan dan wajib mencantumkan keterangan tidak halal pada produk. UU No.33 Tahun 2014 berlaku mulai tanggal 17 Oktober 2019. Dengan adanya kebijakan tersebut, diperlukan sosialisasi kepada produsen kosmetik dalam negeri terkait kewajiban untuk melakukan sertifikasi halal pada produknya. Pemerintah juga perlu menginformasikan terkait prosedur pengajuan sertifikasi dan transparansi biaya yang harus dikeluarkan bagi pelaku usaha tersebut. Selain itu, pemerintah juga perlu mengetahui kendala apa yang dihadapi produsen kosmetik dalam negeri ketika memproduksi produk kosmetik halal serta solusi apa yang sebaiknya perlu dilakukan untuk menghadapi kendala tersebut. Hal ini perlu dilakukan agar Indonesia tidak hanya menjadi negara konsumen kosmetik halal global, tetapi juga dapat menjadi negara produsen kosmetik halal baik di pasar domestik maupun ekspor.

\section{KESIMPULAN}

Karakteristik responden dalam penelitian ini adalah generasi milenial Kota Jakarta Timur yang membeli produk kosmetik berlabel halal MUI yang didominasi berumur antara 20 hingga 24 tahun, menganut agama Islam, berdomisili di Kecamatan Ciracas dengan pendidikan terakhir SMA/ sederajat, bekerja sebagai pegawai swasta dengan pemasukan per bulan Rp 2600000 hingga Rp 5200000 dan pengeluaran pembelian kosmetik sebesar Rp 100000 hingga Rp 250000 per bulan. Mayoritas generasi milenial Kota Jakarta Timur yaitu sebanyak 64 responden mendapatkan sumber informasi mengenai kosmetik dari media sosial. Selanjutnya, merek kosmetik tidak berlabel halal MUI yang dibeli oleh generasi milenial Kota Jakarta Timur didominasi oleh "Maybelline", sedangkan merek kosmetik berlabel halal MUI didominasi oleh "Wardah". 


\section{REFERENSI}

Alfian I, Marpaung M. 2017. Analisis Pengaruh Label Halal, Brand dan Harga

Terhadap Keputusan Pembelian di Kota Medan. At-Tawassuth. Vol 2 (1): 122145.

Anonimous. 2019. State of the Global Islamic Economy Report Driving The Islamic Economy Revolution 4.0. Dinar Standard.

Astogini D, Wahyudin, Wulandari SZ. 2011. Aspek Religiusitas Dalam Keputusan Pembelian Produk Halal (Studi tentang labelisasi halal pada produk makanan dan minuman kemasan). JEBA. Vol 13 (1).

BPOM. Keputusan Kepala Badan Pengawas Obat dan Makanan Republik Indonesia Nomor HK.00.05.4.1745 Tentang Kosmetik.

BPPK KEMENKEU. Badan Pendidikan dan Pelatihan Keuangan Kementerian Keuangan. 2015. Penghasilan Kelas Menengah Naik = Potensi Pajak? [Internet]. Diakses pada: https://bppk.kemenkeu.go.id/id/publikasi/artikel/167-artikelpajak/21014penghasilan-kelas-menengah-naik-potensi-pajak.

Badan Pusat Statistik. 2016. Proyeksi Penduduk Menurut Kecamatan di Kota Bekasi, $2010 \quad-\quad 2020 \quad$ [Internet]. Diakses pada: https://bekasikota.bps.go.id/statictable/2016/12/16/22/proyeksi-pendudukmenurut-kecamatan-di-kota-bekasi-2010---2020-proyeksi-penduduk-menurutkecamatan-di-kota-bekasi-2010---2020-.html

Badan Pusat Statistik. 2018. Jumlah Penduduk dan Laju Pertumbuhan Penduduk di Kota Bandung $2011 \quad-\quad 2016 \quad$ [Internet]. Diakses pada: https://bandungkota.bps.go.id/statictable/2017/08/29/106/-jumlah-pendudukdan-laju-pertumbuhan-penduduk-di-kota-bandung-2011---2016-.html.

Badan Pusat Statistik. 2018. Jumlah Penduduk dan Laju Pertumbuhan Penduduk Menurut Kabupaten/Kota di Provinsi Jawa Timur, 2010, 2016 dan 2017 [Internet]. Diakses pada: https://jatim.bps.go.id/statictable/2018/10/29/1324/jumlah-penduduk-danlaju-pertumbuhan-penduduk-menurut-kabupaten-kota-di-provinsi-jawa-timur2010-2016-dan-2017.html.

Badan Pusat Statistik. 2018. Penduduk Menurut Kelompok Umur dan Jenis Kelamin (Jiwa), 2015-2016 [Internet]. Diakses pada: https://jaktimkota.bps.go.id/dynamictable/2018/01/16/34/penduduk-menurutkelompok-umur-dan-jenis-kelamin-jiwa-2015-2016.html.

Firdaus M, Harmini, Afendi FM. 2011. Aplikasi Metode Kuantitatif untuk Manajemen dan Bisnis. Bogor (ID): IPB Press.

Hosmer DW, Lemeshow S. 2000. Applied Logistic Regression. New York: John Wiley and Sons.

Jannah N. 2018. Pengaruh Jumlah Penduduk dan Produk Domestik Regional Bruto Terhadap Pembiayaan Bank Syariah di Sumatera Utara. At-Tawassuth. Vol 3(2): 224-244. 
Kementerian Perindustrian Republik Indonesia. 2018. Industri Kosmetik Nasional Tumbuh 20\% [Internet]. Diakses pada: https://kemenperin.go.id/artikel/18957/Industri-Kosmetik-Nasional-Tumbuh$20, \% 202018$.

Kementerian Perindustrian Republik Indonesia. 2018. Kinerja Industri Kosmetik Nasional Lampaui Pertumbuhan Ekonomi [Internet]. Diakses pada: https://kemenperin.go.id/artikel/19435/Kinerja-Industri-Kosmetik-NasionalLampaui-Pertumbuhan-Ekonomi.

Kementerian Perindustrian Republik Indonesia. 2020. Perubahan Gaya Hidup Dorong Industri Kosmetik [Internet]. Diakses pada: https://www.kemenperin.go.id/artikel/21460/Perubahan-Gaya-Hidup-DorongIndustri-Kosmetik.

Kementerian Pemberdayaan Perempuan dan Perlindungan Anak. 2018. Statistik Gender Tematik: Profil Generasi Milenial Indonesia. Jakarta (ID).

Khalek AA, Ismail SHS. 2015. Why Are We Eating Halal - Using the Theory of Planned Behavior in Predicting Halal Food Consumption among Generation $Y$ in Malaysia. International Journal of Social Science and Humanity. Vol 5 (7): 608612.

Khansa L. 2019. Faktor-Faktor yang Memengaruhi Keputusan Pembelian Generasi Z Muslim Terhadap Produk Kosmetik Berlabel Halal MUI (Studi Kasus Kota Bogor) .Skripsi. IPB University: Tidak diterbitkan.

Komite Nasional Ekonomi dan Keuangan Syariah. 2019. Masyarakat Indonesia Habiskan USD 40 Miliar untuk Industri Halal di 2017, Pemerintah Perluas Komitmen Halal Lifestyle ke Milenial [Internet]. Diakses pada: https://knks.go.id/berita/15/masyarakat-indonesia-habiskan-usd-40-miliaruntuk-industri-halal-di-2017-pemerintah-perluas-komitmen-halal-lifestyle-kemilenial? category $=3$

Komite Nasional Ekonomi dan Keuangan Syariah. 2019. Mendorong Ekspor Indonesia Melalui Industri Halal [Internet]. Diakses pada: https://knks.go.id/berita/141/mendorong-ekspor-indonesia-melalui-industrihalal?category $=1$

Kotler P, Keller KL. 2009. Manajemen Pemasaran Edisi Ketiga Belas. Jakarta (ID): PT Indeks.

Lembaga Pengkajian Pangan Obat Obatan dan Kosmetika Majelis Ulama Indonesia. 2017. Sertifikat Halal MUI [Internet]. Diakses pada: http://www.halalmui.org/mui14/main/page/sertifikat-halal-mui.

Paramita GP. 2016. Faktor-Faktor yang Memengaruhi Mahasiswa Mengonsumsi Kosmetik Berlabel Halal .Skripsi. IPB University: Tidak dipublikasikan. 
Riduwan, Sunarto. 2011. Pengantar Statistika untuk Penelitian Pendidikan, Sosial, Ekonomi dan Bisnis. Bandung (ID): Alfabeta.

Santoso S. 2003. Statistik Diskriptif: Konsep dan Aplikasi dengan Microsoft Excel dan SPSS. Yogyakarta (ID): ANDI.

Stafford DE, Griffis HS. 2008. A Review of Millennial Generation Characteristics and MilitaryWorkforce Implications. Virginia (USA): CNA Corporation.

Subandowo M. 2017. Peradaban dan Produktivitas dalam Perspektif Bonus Demografi serta Generasi Y dan Z. Sosiohumanika: Jurnal Pendidikan Sains Sosial dan Kemanusiaan. Vol 10 (2): 191-208.

Sugiarto et al. 2000. Ekonomi Mikro Suatu Pendekatan Praktis. Jakarta (ID): PT Gramedia Pustaka Utama. 